\title{
The effect of intravenous administration of liposomal curcumin in addition to sumatriptan treatment in an experimental migraine model in rats
}

This article was published in the following Dove Press journal:

International Journal of Nanomedicine

\author{
Adriana E Bulboacă' \\ Sorana D Bolboacă ${ }^{2}$ \\ loana C Stănescu ${ }^{3}$ \\ Carmen A Sfrângeu' \\ Alina Porfire ${ }^{4}$ \\ Lucia Tefas ${ }^{4}$ \\ Angelo C Bulboacă ${ }^{3}$
}

'Department of Pathophysiology, luliu Hațieganu University of Medicine and Pharmacy Cluj-Napoca, Cluj-Napoca, Romania; ${ }^{2}$ Department of Medical Informatics and Biostatistics, luliu Hațieganu University of Medicine and Pharmacy Cluj-Napoca, ClujNapoca, Romania; ${ }^{3}$ Department of Neurology and Pediatric Neurology, Iuliu Hațieganu University of Medicine and Pharmacy Cluj-Napoca, ClujNapoca, Romania; ${ }^{4}$ Department of Pharmaceutical Technology and Biopharmaceutics, luliu-Hațieganu University of Medicine and Pharmacy Cluj-Napoca, Cluj-Napoca, Romania
Correspondence: Sorana D Bolboacă Department of Medical Informatics and Biostatistics, luliu Hațieganu University of Medicine and Pharmacy Cluj-Napoca, Louis Pasteur Str., No 6, 400349

Cluj-Napoca, Romania

Tel +40 766 34 I 408

Fax +40 264893547

Email sbolboaca@umfcluj.ro
Background: Curcumin has antioxidative properties that could be useful in various diseases due to its ability to act on multiple targets of various cellular pathways. We aimed to assess the efficacy of liposomal curcumin compared with curcumin solution, when in addition to sumatriptan (ST) treatment, in an experimental migraine model induced with nitroglycerin (NTG) in rats. Methods: Seven groups of 9 rats each were investigated: control group without migraine $(1 \mathrm{~mL}$ saline solution intraperitoneal injection [ip]), control group with induced migraine, NTG+ST group (ST), NTG+ST+curcumin1 (CC1) group - $1 \mathrm{mg} / 100 \mathrm{~g}$ body weight (bw), NTG+ST+CC2 - 2 $\mathrm{mg} / 100 \mathrm{~g}$ bw, NTG+ST+liposomal curcumin 1 (1CC1) group - $1 \mathrm{mg} / 100 \mathrm{~g}$ bw, and NTG+ST+1CC2 (1CC2) group - $2 \mathrm{mg} / 100 \mathrm{~g}$ bw. NTG and ST were administered as $1 \mathrm{~mL}$ ip NTG | $1 \mathrm{mg} / 100 \mathrm{~g}$ bw and $1 \mathrm{~mL}$ ip ST | $1 \mathrm{mg} / 100 \mathrm{~g}$ bw, respectively. Plasma total oxidative stress (TOS), malondialdehyde (MDA), nitric oxide (NOx), thiol levels, as well as total antioxidative capacity (TAC) were assessed. The nociception process was assessed by counting the number of flinches and shakes after the formalin test.

Results: The plasma TOS, MDA, and NOx levels, as oxidative stress parameters, were significantly decreased in the curcumin-treated groups, especially where curcumin was in liposomal form. The thiol and TAC were also improved by the curcumin treatment, with the best results obtained for the liposomal curcumin. The closest number of flinches and shakes to the control group was obtained for the group treated with liposomal curcumin at a dose of $2 \mathrm{mg} / 100 \mathrm{~g}$ bw. Conclusion: Liposomal curcumin in a dose of $2 \mathrm{mg} / 100 \mathrm{~g}$ bw when in addition to ST treatment could be an optimum therapeutic strategy for migraine attacks and could represent a base for future clinical research and application.

Keywords: rats, migraine disorder, liposomal curcumin, serotonin, oxidative stress, nociception

\section{Introduction}

The Global Burden of Disease Study reported tension-type headache and migraine as the second most prevalent disorders in the world. ${ }^{1}$ There is still insufficient knowledge about the mechanisms of migraine, and different treatment strategies are currently under research (both preventive therapy and acute therapy for migraine attack). The neurogenic vasodilation is one of the most important mechanisms of migraine due to an excessive production of nitric oxide (NO) that activates a long-lasting central mechanism of hyperalgesia. ${ }^{2}$ Consequently, the experimental migraine induced by nitroglycerin (NTG) administration (an NO donor) is one of the most reliable experimental models for migraine inducement in rats. ${ }^{3}$ NTG-induced hyperalgesia can be evaluated by assessment of the 
nociceptive behavior evoked by the formalin test. ${ }^{2}$ Common migraine triggers are capable of generating oxidative stress, and oxidative-stress molecules released during migraine attack can contribute to nociceptive mechanism. ${ }^{4,5}$ The nitro-oxidative stress and the inflammatory response play a major role in the onset and development of neuropathic pain, and antioxidant supplementation therapy seems to be useful. ${ }^{6}$ Considering these pieces of evidence assessing the oxidative stress during migraine attack could be useful for nociception evaluation as well as for establishing the treatment's efficiency.

The preemptive analgesic and antioxidant effects of curcumin following oral administration in an experimental migraine model induced by NTG in rats have been previously demonstrated. ${ }^{7,8}$ Because the bioavailability of curcumin administered orally is poor, primarily due to poor absorption, rapid metabolism, and fast elimination, ${ }^{9}$ in our study we opted for the parenteral administration of curcumin. Following parenteral administration, namely the intravenous route, curcumin nanoformulation (such as curcumin-loaded liposomes and polymeric nanoparticles obtained from acrylic polymers or poly(lactic-co-glycolic acid)), has been shown to reach the central nervous system parenchyma by crossing the blood-brain barrier (BBB).${ }^{10}$ Curcumin solutions were also administered by intravenous route for its anti-inflammatory properties in adjuvant-induced arthritis in rats. ${ }^{11}$ In a clinical trial, nanocurcumin plus omega-3 fatty acids supplementation have been shown to reduce both the attack frequency and the ICAM-1 (adhesion molecule associated with inflammation) serum level in patients with migraine. ${ }^{12}$ Therefore, nanoformulations of curcumin have been developed for their superior therapeutic efficiency in inflammatory and oxidative stress processes..$^{13,14}$

The serotoninergic system represents one of the most important pathophysiological mechanisms of migraine; 5-hydroxytryptamine1 (5-HT1) receptor agonists are known to be effective in the treatment of migraine attacks. ${ }^{15}$ The 5-HT1 receptors are subdivided into 5-HT1A-D, and the effect of triptans is related to $5-\mathrm{HT} 1 \mathrm{~B} / 1 \mathrm{D}$ receptor occupancy. ${ }^{16}$ Consequently, one of the pathological mechanisms of migraine attack is related to the activation of 5-HT1 receptors in the brain and their genotype. ${ }^{15}$ The plasmatic level of 5-HT decreases, and the concentration of its metabolite, hydroxyindoleacetic acid, increases between attacks and decreases during the attack. ${ }^{17}$ A low concentration of 5-HT facilitates the activation of the trigeminovascular pathway induced by cortical spreading depression. ${ }^{18}$ It was also demonstrated that about a half of the rat trigeminal ganglion neurons contain nitric oxide. ${ }^{19}$ Depletion of serotonin, a vasoconstrictor, would leave the vasodilator nitric oxide to trigger the migraine attack in experimental migraine in rats. ${ }^{20}$ One of the most effective drugs for migraine attack is sumatriptan (ST), a selective 5-HT1 receptor agonist. Additionally, ST can also produce a transient increase in systolic and diastolic blood pressure when it is administered by intravenous route. ${ }^{21}$ Even though there are several limitations of triptan treatment (serotonin syndrome with symptoms that include agitation, diarrhea, nausea, and loss of coordination), ${ }^{22}$ ST remains one of the most widely used treatments for migraine attack. ${ }^{21}$ The antioxidant effect of curcumin (including the reduction of nitro-oxidative stress and NO plasma concentration during experimental migraine) and its analgesic properties have been previously demonstrated. ${ }^{7,8}$ Our study aimed to compare the effect of single ST administration with the association of ST and curcumin for the treatment of migraine attacks in an experimental migraine model induced with NTG in rats and to observe if there is a synergistic effect of ST and curcumin on oxidative stress. Because the absorption of curcumin after oral administration is limited, our experiment was designed to observe the effect of curcumin-loaded liposomes following intravenous administration, in addition to ST treatment.

\section{Materials and methods Materials}

ST (Imigran) was purchased from GlaxoSmithKline PLC (London, UK). Curcumin ( $\geq 94 \%$ curcuminoid content; $\geq 80 \%$ curcumin) and cholesterol were purchased from Sigma-Aldrich Co. (St Louis, MO, USA). 1,2-Dipalmitoylsn-glycero-3-phosphocholine (DPPC, $\geq 99 \%$ [TP-PC]) and N-(carbonyl-methoxypolyethylenglycol-2000)-1,2distearoyl-sn-glycero-3-phosphoethanolamine (PEG-2000DSPE, $\geq 98 \%$ [HPLC]) sodium salt were purchased from Lipoid GmbH (Ludwigshafen, Germany). All other chemicals were of analytical grade.

\section{Experimental model}

This experimental study used Wistar-Bratislava albino male rats (from the Animal Department of the University of Medicine and Pharmacy in Cluj-Napoca), weighing 200-250 g. The animals were kept at the Pathophysiology Department in polypropylene cages at constant temperature $\left(24^{\circ} \mathrm{C} \pm 2^{\circ} \mathrm{C}\right)$, humidity $(60 \% \pm 5 \%)$, and light-dark regime. The animals had free access to standard pellets (Cantacuzino Institute, Bucharest, Romania) and to water ad libitum.

The rats were randomly divided in 7 groups containing 9 animals/group: one control group without migraine (C), one control group with induced migraine (NTG-C), one group with ST only, two groups with ST and different 
doses of curcumin solution (NTG+ST+curcumin1 [CC1] and $\mathrm{NTG}+\mathrm{ST}+\mathrm{CC} 2$ ), and two groups treated with $\mathrm{ST}$ and different doses of liposomal curcumin (NTG+ST+liposomal curcumin $1[1 \mathrm{CC} 1]$ and $\mathrm{NTG}+\mathrm{ST}+\mathrm{lCC} 2)$, as presented in Table 1.

\section{Preparation of liposomal curcumin}

Liposomal curcumin was prepared as PEG-coated nanoliposomes using the film hydration method, as previously described. ${ }^{23}$ Briefly, the phospholipids were used in a concentration of $70 \mathrm{mM}$, of which $66.5 \mathrm{mM}$ DPPC, the main lipid, and 3.5 mM PEG-2000-DSPE, a PEG-derived phospholipid, to achieve long circulation properties and an increased therapeutic efficiency. Cholesterol was added to the lipid mixture in 10:1 phospholipids to cholesterol molar ratio. Liposomal curcumin was characterized for mean particle size, polydispersity value, zeta potential, curcumin content, and encapsulation efficiency. ${ }^{22,24}$ Thus, liposomal curcumin had a size around $140 \mathrm{~nm}$; a low polydispersity value, close to 0.1 ; and a zeta potential of about $-50 \mathrm{mV}$. The size, size distribution, and surface charge of the liposomes were determined immediately after preparation, upon dilution in a ratio of 1:100. The presented method led to an efficient encapsulation of curcumin in the liposomes, the encapsulation efficiency being close to $80 \%$, and so the formulation contained a relatively high concentration of curcumin, around $4.7 \mathrm{mg} / \mathrm{mL}$. On the other hand, a curcumin solution was prepared by dissolution in $96 \%$ (v/v) ethanol and was further diluted with saline to achieve the same curcumin concentration as in the liposomal formulation.

\section{ST and curcumin administration}

In the NTG+ST group, ST at a dose of $1 \mathrm{mg} / \mathrm{kg}$ body weight (bw) was injected ip 30 min after the NTG injection, in accordance with previous studies. ${ }^{25,26}$ Curcumin was administered intravenous administration immediately after ST, in the dorsal vein of the tail, according to Chiu et al. ${ }^{10}$

\section{Formalin test}

The formalin test, for nociception assessment, was performed $4 \mathrm{~h}$ after the NTG administration ${ }^{8}$ and was carried out as described by Tjølsen et al. ${ }^{27}$ Diluted formalin ( $1 \%$ in saline) was injected subcutaneously in the right paw of the animals. After the formalin injection, animals were kept in plexiglass cages for observation. Two distinct phases were assessed. The number of flinches and shakes (rapid and brief withdraws or flexions of the injected paw) per min were assessed during 1-5 min after the formalin injection (Phase I) and for 1-min periods at 5-min intervals during 10-60 min after the formalin injection (Phase II). The vasodilator effect consecutive to a noxious stimulus is characteristic of the first phase, whereas the inflammatory mechanism induced by noxious stimuli is the central phenomenon in the second phase. ${ }^{28}$

\section{Measurements}

The oxidative stress parameters were quantified from blood samples collected from the retro-orbital plexus of each rat, under ketamine anesthesia $\left(5 \mathrm{mg} / \mathrm{kg}\right.$ bw, ip route) ${ }^{29} \mathrm{The}$ animals were euthanized at the end of the experiment by cervical dislocation. The following oxidative stress parameters were assessed:

Table I Groups by inducement and treatment regimens

\begin{tabular}{|c|c|c|}
\hline Group & Abbreviation & Administration route $\mid$ dose \\
\hline I (control) & C & I mL ip saline solution $(0.9 \%)$ \\
\hline 2 (NTG control) & NTG-C & I $\mathrm{mL}$ ip NTG | I mg/l00 g bw \\
\hline $3(\mathrm{NTG}+\mathrm{ST})$ & $\mathrm{NTG}+\mathrm{ST}$ & $\begin{array}{l}\text { I } \mathrm{mL} \text { ip NTG | I mg//00 g bw } \\
\text { I mL ip ST | I } \mathrm{mg} / 100 \mathrm{~g} \text { bw }\end{array}$ \\
\hline 4 (NTG+ST+curcumin I) & $\mathrm{NTG}+\mathrm{ST}+\mathrm{CCl}$ & $\begin{array}{l}\text { I } \mathrm{mL} \text { ip NTG | I mg// } 00 \mathrm{~g} \mathrm{bw} \\
\text { I } \mathrm{mL} \text { ip ST | I } \mathrm{mg} / \mathrm{I} 00 \mathrm{~g} \mathrm{bw} \\
\text { I } \mathrm{mL} \text { iv curcumin solution | I } \mathrm{mg} / 100 \mathrm{~g} \mathrm{bw}\end{array}$ \\
\hline 5 (NTG+ST+curcumin2) & $\mathrm{NTG}+\mathrm{ST}+\mathrm{CC} 2$ & $\begin{array}{l}\text { I } \mathrm{mL} \text { ip NTG | I mg/l00 g bw } \\
\text { I } \mathrm{mL} \text { ip ST | I mg/l00 g bw } \\
\text { I } \mathrm{mL} \text { iv curcumin solution | } 2 \mathrm{mg} / \mathrm{I} 00 \mathrm{~g} \text { bw }\end{array}$ \\
\hline 6 (NTG+ST+liposomal curcumin I) & $\mathrm{NTG}+\mathrm{ST}+\mathrm{ICC}$ & $\begin{array}{l}\text { I } \mathrm{mL} \text { ip NTG | I mg//00 g bw } \\
\text { I } \mathrm{mL} \text { ip ST | I mg// } 00 \mathrm{~g} \text { bw } \\
\text { I } \mathrm{mL} \text { iv liposomal curcumin | I mg/ } / 00 \mathrm{~g} \text { bw }\end{array}$ \\
\hline 7 (NTG+ST+liposomal curcumin2) & $\mathrm{NTG}+\mathrm{ST}+\mathrm{ICC} 2$ & $\begin{array}{l}\text { I } \mathrm{mL} \text { ip NTG | I mg/ } 100 \mathrm{~g} \text { bw } \\
\text { I } \mathrm{mL} \text { ip ST | I mg//00 g bw } \\
\text { I } \mathrm{mL} \text { iv liposomal curcumin | } 2 \mathrm{mg} / \mathrm{I} 00 \mathrm{~g} \text { bw }\end{array}$ \\
\hline
\end{tabular}

Abbreviations: bw, body weight; CC, curcumin; ip, intraperitoneal injection; iv, intravenous administration; ICC, liposomal curcumin; NTG, nitroglycerin; ST, sumatriptan. 
- oxidative stress intensity: malondialdehyde (MDA), ${ }^{30}$ the indirect assessment of nitric oxide (NOx) synthesis, and total oxidative status (TOS) $)^{31}$

- the antioxidant capacity of the plasma: thiol ${ }^{32}$ and total antioxidative capacity (TAC) ${ }^{30}$

A Jasco V-350 UV-VIS spectrophotometer (Jasco International Co, Ltd, Tokyo, Japan) was used for all spectroscopic measurements.

\section{Statistical analysis}

The data were analyzed using Statistica program (v.8, StatSoft) and presented as mean $\pm \mathrm{SD}$, and as median and interquartile ranges (expressed as [Q1-Q3], where Q1 and Q3 are the value of the first and third quartiles). Statistical comparisons between groups were performed using the twotailed Mann-Whitney test at a significance level of 5\%. All graphs were plotted using Microsoft Excel 2016.

\section{Ethics statement}

The Ethics Committee of Iuliu-Haţieganu University of Medicine and Pharmacy Cluj-Napoca (454/20.12.2017) approved the study. All procedures performed in this study were in accordance with the ethical standards of the institutional research committee and with the 1964 Helsinki Declaration and its later amendments or comparable ethical standards. All applicable international, national, and institutional guidelines for the care and use of animals were followed.

\section{Results}

The parameters that reflect the oxidative stress intensity varied as expected among groups. The lowest values were obtained for the group treated with liposomal curcumin at a dose of $2 \mathrm{mg} / 100 \mathrm{~g}$ bw. For different groups treated with curcumin, the highest mean values of the oxidative stress parameters were observed in the $\mathrm{NTG}+\mathrm{ST}+\mathrm{CC} 1$ group for MDA and in the NTG+ST+CC2 group for NOx and TOS. The lowest values for the parameters related to the antioxidant capacity of plasma were observed for the NTG+ST group. The highest concentration of thiol and TAC were found in the NTG+ST+1CC2 group. The statistical summary of the oxidative stress parameters is presented in Tables 2 (oxidative stress intensity parameters) and 3 (antioxidant capacity of plasma).

The MDA values were significantly different compared to control for all groups treated with curcumin, either conventional or liposomal $(p<0.0004)$. The smallest variability in MDA values was observed for the $\mathrm{NTG}+\mathrm{ST}+\mathrm{CC} 1$ group, with significant differences in all groups treated with curcumin compared to the control group (C), NTG group, or NTG+ST group (Figure 1A). Such as the MDA values, the NOx values were significantly different compared to control for all groups that received curcumin, either conventional or liposomal $(p<0.0004)$. No significant differences were observed between the groups treated with the same type of curcumin but at different concentrations (conventional

Table 2 Quantification of oxidative stress intensity by groups

\begin{tabular}{|c|c|c|c|c|}
\hline Group & Statistics & MDA (pmol/L) & NOx $(\mu \mathrm{mol} / \mathrm{L})$ & TOS ( $\mu \mathrm{mol} / \mathrm{L})$ \\
\hline \multirow[t]{2}{*}{ C } & Mean \pm SD & $2.59 \pm 0.06$ & $14.89 \pm 2.03$ & $26.56 \pm 1.67$ \\
\hline & Median (QI-Q3) & $2.61(2.55-2.62)$ & $15(14-17)$ & $26(25-27)$ \\
\hline \multirow[t]{2}{*}{ NTG-C } & Mean \pm SD & $4.66 \pm 0.13$ & $37.89 \pm 2.67$ & $46.00 \pm 2.24$ \\
\hline & Median (QI-Q3) & $4.66(4.56-4.75)$ & $37(36-40)$ & $46(45-46)$ \\
\hline \multirow[t]{2}{*}{$\mathrm{NTG}+\mathrm{ST}$} & Mean \pm SD & $4.33 \pm 0.09$ & $35.00 \pm 3.54$ & $36.78 \pm 3.99$ \\
\hline & Median (QI-Q3) & $4.33(4.29-4.4)$ & $35(3 \mathrm{I}-38)$ & $36(35-40)$ \\
\hline \multirow[t]{2}{*}{$\mathrm{NTG}+\mathrm{ST}+\mathrm{CCl}$} & Mean \pm SD & $4.20 \pm 0.02$ & $32.22 \pm 2.86$ & $33.56 \pm 3.68$ \\
\hline & Median (QI-Q3) & $4.2(4 . \mid 9-4.2 I)^{a, e, i}$ & $33(30-35)^{A, E}$ & $35(3 I-36)^{* 1, \# 4}$ \\
\hline \multirow[t]{2}{*}{$\mathrm{NTG}+\mathrm{ST}+\mathrm{CC} 2$} & Mean \pm SD & $3.95 \pm 0.40$ & $32.78 \pm 1.30$ & $35.89 \pm 1.76$ \\
\hline & Median (QI-Q3) & $4(3.9-4.2)^{b, f, j, m}$ & $33(32-33)^{\mathrm{B}, \mathrm{F}}$ & $36(35-37) * 2, \# 5$ \\
\hline \multirow[t]{2}{*}{$\mathrm{NTG}+\mathrm{ST}+\mathrm{ICCl}$} & Mean \pm SD & $3.5 I \pm 0.23$ & $23.22 \pm 1.99$ & $26.78 \pm 2.73$ \\
\hline & Median (QI-Q3) & $3.5(3.39-3.67)^{\mathrm{c.g.k} k}$ & $23(22-25)^{\mathrm{C}, \mathrm{G}, \mathrm{I}}$ & $27(26-29)^{\# 6, \# 8}$ \\
\hline \multirow[t]{2}{*}{$\mathrm{NTG}+\mathrm{ST}+\mathrm{ICC} 2$} & Mean \pm SD & $3.11 \pm 0.24$ & $21.33 \pm 2.18$ & $22.67 \pm 1.80$ \\
\hline & Median (QI-Q3) & $3.12(2.89-3.23)^{\mathrm{d}, \mathrm{h}, \mathrm{l}, \mathrm{n}}$ & $21(20-23)^{\mathrm{D}, \mathrm{H}, \mathrm{J}}$ & $23(21-24)^{* 3, \# 7, \# 9, \pm 10}$ \\
\hline
\end{tabular}

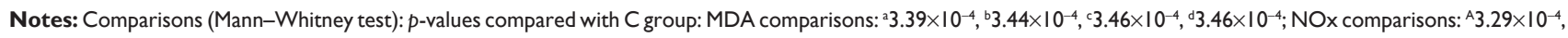

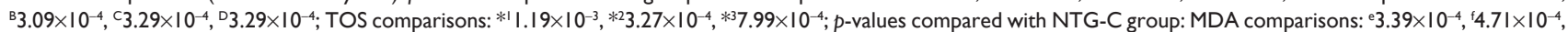
$83.46 \times 10^{-4},{ }^{\mathrm{h}} 3.46 \times 10^{-4}$; NOx comparisons: ${ }^{\mathrm{E}} \mathrm{I.58} \times 10^{-3},{ }^{\mathrm{F}} 4.36 \times 10^{-4},{ }^{6} 3.39 \times 10^{-4},{ }^{\mathrm{H}} 3.39 \times 10^{-4}$; TOS comparisons: ${ }^{* 4} 3.20 \times 10^{-4}$, ${ }^{\# 5} 3.18 \times 10^{-4}$, ${ }^{\# 6} 3.20 \times 10^{-4},{ }^{\# 7} 3.18 \times 10^{-4}$; $p$-values

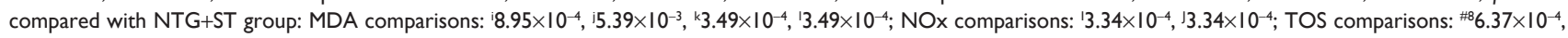
${ }^{\# 9} 3.32 \times 10^{-4}$; $p$-values compared with $\mathrm{NTG}+\mathrm{ST}+\mathrm{CCl}$ group: MDA comparisons: ${ }^{\mathrm{m}} 4.62 \times 10^{-2}$; $p$-value compared with $\mathrm{NTG}+\mathrm{ST}+\mathrm{ICCl}: \mathrm{MDA}$ comparisons: ${ }^{n} 6.17 \times 10^{-3}$; TOS comparisons: ${ }^{ \pm 10} 5.96 \times 10^{-3}$.

Abbreviations: C, control; CC, curcumin; ICC, liposomal curcumin; MDA, malondialdehyde; NOx, nitric oxide; NTG, nitroglycerin; QI, 25th percentile; Q3, 75th percentile; ST, sumatriptan; TOS, total oxidative status. 
Table 3 Quantification of antioxidant capacity by groups

\begin{tabular}{|c|c|c|c|}
\hline Group & Statistics & Thiol (mg\%) & TAC (Eq/L) \\
\hline \multirow[t]{2}{*}{ C } & Mean \pm SD & $208.00 \pm 3.84$ & $1.23 \pm 0.03$ \\
\hline & Median (QI-Q3) & $207(207-210)$ & $1.23(1.2-1.24)$ \\
\hline \multirow[t]{2}{*}{ NTG-C } & Mean \pm SD & $|82.56 \pm 5.6|$ & $1.08 \pm 0.04$ \\
\hline & Median (QI-Q3) & $183(178-187)$ & $1.07(\mathrm{I} .06-\mathrm{I} . \mathrm{I})$ \\
\hline \multirow[t]{2}{*}{ NTG+ST } & Mean \pm SD & $185.78 \pm 7.19$ & $1.12 \pm 0.06$ \\
\hline & Median (QI-Q3) & $185(179-189)$ & $1.12(1.11-1.16)$ \\
\hline \multirow[t]{2}{*}{$\mathrm{NTG}+\mathrm{ST}+\mathrm{CCl}$} & Mean \pm SD & $189.33 \pm 5.20$ & $1.16 \pm 0.30$ \\
\hline & Median (QI-Q3) & $191(189-192)^{\mathrm{a}, \mathrm{e}}$ & $1.08(1.04-1.09)^{\mathrm{A}}$ \\
\hline \multirow[t]{2}{*}{$\mathrm{NTG}+\mathrm{ST}+\mathrm{CC2}$} & Mean \pm SD & $193.67 \pm 5.10$ & $1.37 \pm 0.18$ \\
\hline & Median (QI-Q3) & $195(190-198)^{\mathrm{b}, \mathrm{fi}}$ & $1.37(\mathrm{I} .2 \mathrm{I}-\mathrm{I} .45)^{\mathrm{D}, \mathrm{G}}$ \\
\hline \multirow[t]{2}{*}{$\mathrm{NTG}+\mathrm{ST}+\mathrm{ICCl}$} & Mean \pm SD & $217.56 \pm 4.28$ & $1.44 \pm 0.05$ \\
\hline & Median (QI-Q3) & $218(2 \mid 3-222)^{(\mathrm{c}, \mathrm{g} .1}$ & $\mathrm{I} .44(\mathrm{I} .4-\mathrm{I} .47)^{\mathrm{B}, \mathrm{E}, \mathrm{H}, \mathrm{J}}$ \\
\hline \multirow[t]{2}{*}{ NTG+ST+ICC2 } & Mean \pm SD & $225.56 \pm 4.69$ & $1.55 \pm 0.09$ \\
\hline & Median (QI-Q3) & $226(223-229)^{d, h, k, k}$ & $1.58(I .5 I-I .6 I)^{C, F, I, K}$ \\
\hline
\end{tabular}

Notes: Comparisons (Mann-Whitney test): $p$-values compared with C group: thiol comparisons: ${ }^{\mathrm{a} 3} 3.34 \times 10^{-4},{ }^{\mathrm{b}} 3.34 \times 10^{-4},{ }^{\mathrm{c}} 8.95 \times 10^{-4},{ }^{\mathrm{d}} 3.39 \times 10^{-4}$; $\mathrm{TAC}$ comparisons: ${ }^{\mathrm{A}} 5.29 \times 10^{-3}$, ${ }^{\mathrm{B}} 3.44 \times 10^{-4},{ }^{\mathrm{C}} 3.44 \times 10^{-4}$; $p$-values compared with NTG-C group: thiol comparisons: ${ }^{\mathrm{e}} \mathrm{I} .46 \times 10^{-2},{ }^{\mathrm{f}} \mathrm{I} .65 \times 10^{-3},{ }^{8} 3.39 \times 10^{-4},{ }^{\mathrm{h}} 3.44 \times 10^{-4}$; TAC comparisons: ${ }^{\mathrm{D}} 3.4 \mathrm{I} \times 10^{-4}$, E3.4I $\times 10^{-4}$,

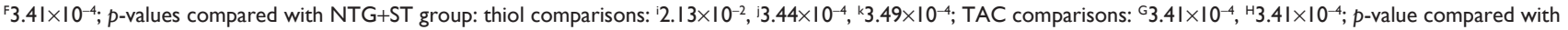

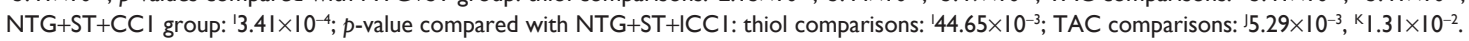

Abbreviations: C, control; CC, curcumin; ICC, liposomal curcumin; NTG, nitroglycerin; QI, 25th percentile; Q3, 75th percentile; ST, sumatriptan; TAC, total antioxidative capacity.

A

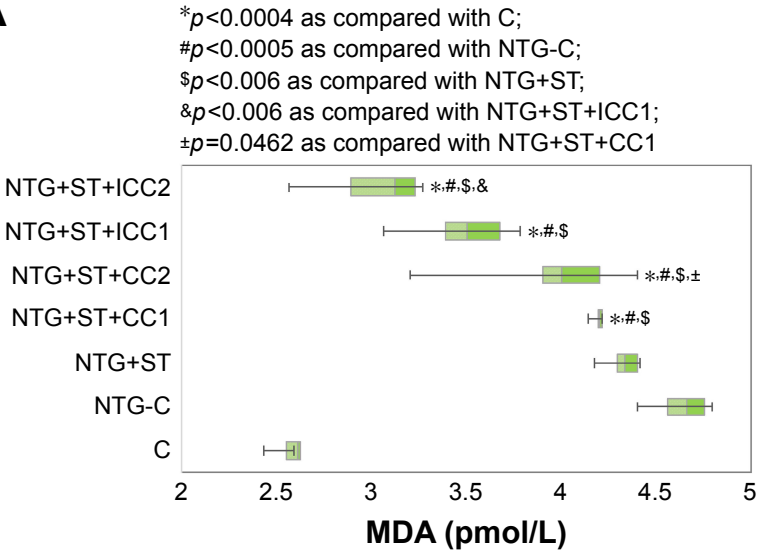

B
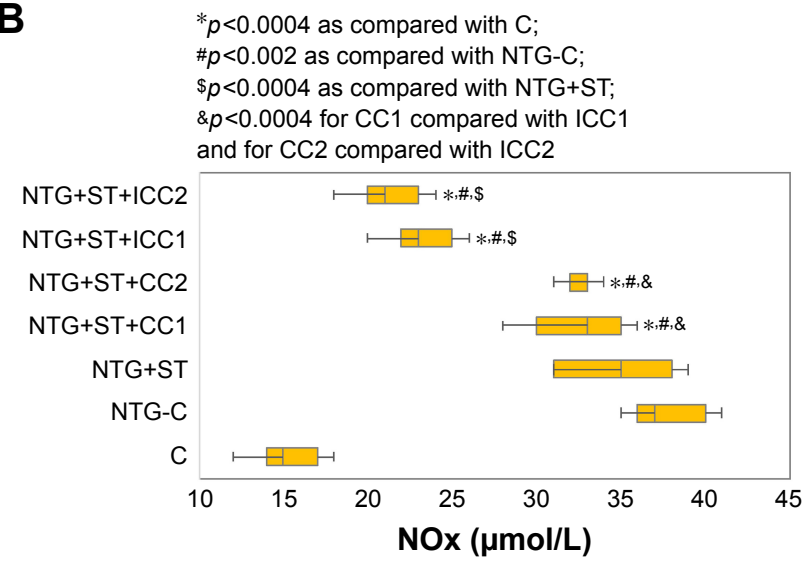

C

${ }^{*} p<0.0012$ as compared with $\mathrm{C}$; $\# p<0.0003$ as compared with NTG-C; $\$ p<0.0006$ as compared with NTG+ST; $\& p<0.0030$ for CC1 compared with ICC1 and for CC2 compared with ICC2

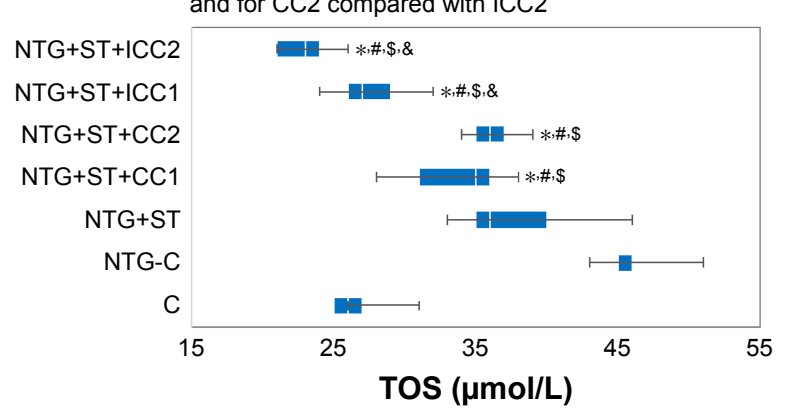

Figure I Parameters of oxidative stress intensity by groups. (A) MDA, (B) NOx, (C) TOS. The box is given by the values of the first and third quartiles, the mid-line is given by the value of the median, and the whiskers are the minimum and maximum values. $\mathrm{C}$ is the control group (no medication), NTG-C is the group treated with nitroglycerin (NTG), NTG+ST is the group treated with NTG and sumatriptan (ST), NTG+ST+CCl is the group treated with NTG+ST and curcumin I mg/l00 g body weight (bw), $\mathrm{NTG}+\mathrm{ST}+\mathrm{CC} 2$ is the group treated with NTG+ST and curcumin $2 \mathrm{mg} / \mathrm{l} 00 \mathrm{~g}$ bw, NTG+ST+ICC is the group treated with NTG+ST and liposomal curcumin I mg/I00 $\mathrm{g}$ bw, and NTG+ST+ICC2 is the group treated with NTG+ST and liposomal curcumin $2 \mathrm{mg} / \mathrm{l} 00 \mathrm{~g}$ bw. Abbreviations: C, control; MDA, malondialdehyde; NOx, nitric oxide; TOS, total oxidative status. 

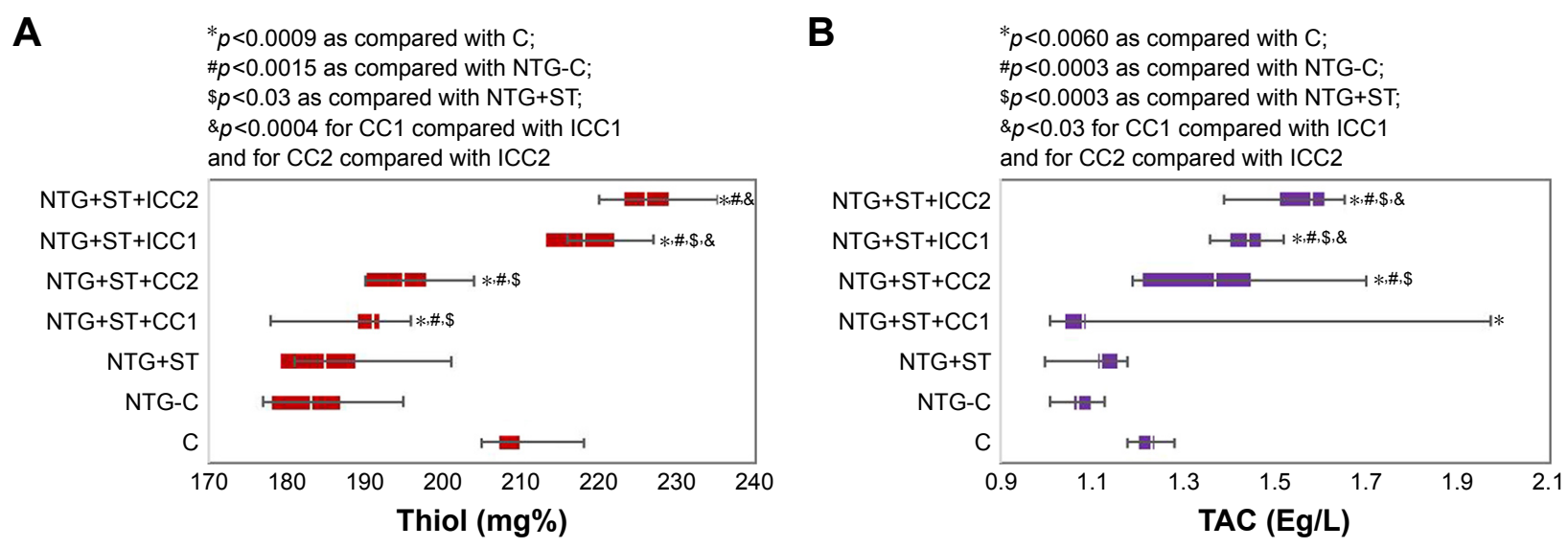

Figure 2 Parameters of antioxidant capacity of plasma by groups: (A) thiol, (B) TAC. The box is given by the values of the first and third quartiles, the mid-line is given by the value of the median, and the whiskers are the minimum and maximum values. $C$ is the control group (no medication), NTG-C is the group treated with nitroglycerin (NTG), NTG+ST is the group treated with NTG and sumatriptan (ST), NTG+ST+CCl is the group treated with NTG+ST and curcumin I mg/l00 g body weight (bw), $\mathrm{NTG}+\mathrm{ST}+\mathrm{CC} 2$ is the group treated with NTG+ST and curcumin $2 \mathrm{mg} / \mathrm{I} 00 \mathrm{~g}$ bw, NTG+ST+ICC is the group treated with NTG+ST and liposomal curcumin I mg/I00 $\mathrm{g}$ bw, and NTG+ST+ICC2 is the group treated with NTG+ST and liposomal curcumin $2 \mathrm{mg} / \mathrm{l} 00 \mathrm{~g}$ bw.

Abbreviations: C, control; TAC, total antioxidative capacity.

curcumin $p=0.75$, liposomal curcumin $p=0.08$ ). Significantly lower NOx values were found when the 1CC2 group was compared to the $\mathrm{CC} 2$ group, and the $1 \mathrm{CC} 1$ group was compared to the $\mathrm{CC} 1$ group (Figure 1B). Except for the $\mathrm{NTG}+\mathrm{ST}+\mathrm{lCC} 1$ group, the TOS values were significantly different compared to the control group (Figure 1C). The TOS values were significantly lower when the NTG+ST group was compared to NTG group ( $p=0.0003$ ). No differences in the TOS concentration were seen when the $\mathrm{CC} 1$ group was compared to the CC2 group ( $p=0.18$ ). The increase in liposomal curcumin dose led to a significant decrease of TOS values $(p=0.01)$.

When compared to the control group, significant values were found for thiol $(p<0.0009)$, with higher values for the groups treated with liposomal curcumin and smaller values for all other groups (Figure 2A). No significant differences in thiol values were observed when NTG was compared with NTG+ST group $(p=0.38)$. Similarly, thiol values were obtained among groups treated with conventional curcumin ( $p=0.18$ ), while the increase in curcumin dose, in liposomal form, led to a significant increase in thiol values $(p=0.005)$.

Except for the NTG+ST+CC2, the TAC values were significantly different compared to the control group. The TAC values were significantly higher in NTG+ST group compared to the NTG group ( $p=0.03$ ). Significantly lower values of TAC were observed at a lower concentration of both conventional curcumin $(p=0.005)$ and liposomal curcumin $(p=0.01)$. The TAC values were significantly lower when the pretreatment consisted of conventional curcumin as opposed to the group treated with liposomal curcumin (Figure 2B).

The smallest number of flinches and shakes in both phases (I and II) were observed for the NTG+ST+lCC2 group (16 in Phase I and 111 in Phase II), whereas the highest was found for the NTG group. The summary of the results obtained in the formalin test is presented in Table 4.

The number of flinches and shakes were significantly different when the pretreatment groups were compared with the control group, with one exception represented by the NTG+ST+1CC2 group (Figure 3). No significant differences with regard to the number of flinches and shakes were observed in the first phase when the $\mathrm{NTG}+\mathrm{ST}+\mathrm{CC} 1$ group was compared to the $\mathrm{NTG}+\mathrm{ST}+\mathrm{CC} 2$ group $(p=0.89)$. In the second phase, the number of flinches and shakes were significantly lower in the group treated with the higher dose of conventional curcumin compared to the group that received the lowest dose of conventional curcumin ( $p=0.01$ ). The number of flinches and shakes were significantly lower in both Phase I ( $p=0.03$ ) and Phase II $(p=0.0003)$ when the group treated with the higher dose of liposomal curcumin was compared to the group with the lowest dose of liposomal curcumin.

\section{Discussion}

NTG-induced hyperalgesia in rats is an experimental model that mimics the action of nitric oxide on amino acid neurotransmitters such as glutamate, which is a signaling molecule for central sensitization. ${ }^{33} \mathrm{NO}$ can cause migraine-like attacks in migraine patients and initiates a self-amplifying process in the trigeminal system, probably due to a central 
Table 4 Descriptive metrics for the formalin test by groups

\begin{tabular}{|c|c|c|c|}
\hline \multirow[t]{2}{*}{ Group } & \multirow[t]{2}{*}{ Statistics } & \multicolumn{2}{|c|}{ No of flinches and shakes } \\
\hline & & Phase I & Phase II \\
\hline \multirow[t]{2}{*}{ C } & Mean $\pm S D$ & $20.11 \pm 1.76$ & $114.11 \pm 2.93$ \\
\hline & Median (QI-Q3) & $20(|9-2|)$ & $114(113-117)$ \\
\hline \multirow[t]{2}{*}{ NTG-C } & Mean \pm SD & $42.22 \pm 2.68$ & $146.44 \pm 9.86$ \\
\hline & Median $(\mathrm{QI}-\mathrm{Q} 3)$ & $42(4 I-44)^{\mathrm{a}}$ & $145(142-150)^{\mathrm{A}}$ \\
\hline \multirow[t]{2}{*}{ NTG+ST } & Mean \pm SD & $27.44 \pm 1.33$ & $|39.89 \pm 4.0|$ \\
\hline & Median (QI-Q3) & $28(27-28)^{\mathrm{b}, \mathrm{f}}$ & I40 (I37-|44) \\
\hline \multirow[t]{2}{*}{$\mathrm{NTG}+\mathrm{ST}+\mathrm{CCl}$} & Mean \pm SD & $27.78 \pm 4.41$ & $136.78 \pm 4.97$ \\
\hline & Median (QI-Q3) & $28(26-32)^{c, g}$ & $138(133-\mid 40)^{C, F}$ \\
\hline \multirow[t]{2}{*}{$\mathrm{NTG}+\mathrm{ST}+\mathrm{CC} 2$} & Mean \pm SD & $27.78 \pm 2.73$ & $|28.78 \pm 5.3|$ \\
\hline & Median (QI-Q3) & $28(25-30)^{\mathrm{d}, \mathrm{h}}$ & $129(|25-| 3 \mid)^{D, G, J, M}$ \\
\hline \multirow[t]{2}{*}{$\mathrm{NTG}+\mathrm{ST}+\mathrm{ICCl}$} & Mean \pm SD & $22.44 \pm 1.88$ & $126.22 \pm 4.38$ \\
\hline & Median (QI-Q3) & $22(2 I-24)^{e, i, k}$ & $127(122-129)^{\mathrm{EH}, \mathrm{K}}$ \\
\hline \multirow[t]{2}{*}{$\mathrm{NTG}+\mathrm{ST}+\mathrm{ICC} 2$} & Mean \pm SD & $19.67 \pm 2.55$ & $115.89 \pm 3.18$ \\
\hline & Median (QI-Q3) & $20(|8-2|)^{\mathrm{j}, \mathrm{l}, \mathrm{m}}$ & $117(113-118)^{\mid, L, N}$ \\
\hline
\end{tabular}

Notes: Comparisons (Mann-Whitney test): $p$-values as compared with $C$ group: Phase I: ${ }^{\mathrm{a}} 3.32 \times 10^{-4}, \mathrm{~b} 3.27 \times 10^{-4}, \mathrm{cl} .40 \times 10^{-3}, \mathrm{~d} 3.36 \times 10^{-4},{ }^{\mathrm{e}} 3.39 \times 10^{-4}$; Phase II: ${ }^{\mathrm{A}} 3.4 \mathrm{I} \times 10^{-4}$, B3.39 $\times 10^{-4},{ }^{\circ} 3.39 \times 10^{-4},{ }^{D} 3.39 \times 10^{-4}, E_{3} 39 \times 10^{-4} ; p$-values as compared with NTG group: Phase I: ${ }^{3} 3.25 \times 10^{-4}, 83.34 \times 10^{-4},{ }^{\mathrm{h}} 3.34 \times 10^{-4}, 3.27 \times 10^{-4}, 13.32 \times 10^{-4}$; Phase II: ${ }^{\mathrm{F}} \mathrm{I} .33 \times 10^{-2},{ }^{\mathrm{G}} \mathrm{I} .07 \times 10^{-3},{ }^{\mathrm{H}} 3.46 \times 10^{-4},{ }^{13.46 \times 10^{-4}}$; $p$-values as compared with NTG+ST

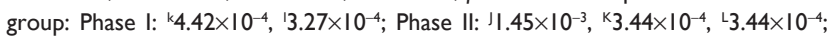
p-value as compared with $\mathrm{NTG}+\mathrm{ST}+\mathrm{CCl}$ group: Phase II: ${ }^{\mathrm{M}} 7.88 \times 10^{-3}$; $p$-value as compared with NTG+ST+ICCI: Phase I: ${ }^{\mathrm{m}} 3.16 \times 10^{-2}$; Phase II: ${ }^{\mathrm{N}} 3.44 \times 10^{-4}$.

Abbreviations: C, control; CC, curcumin; ICC, liposomal curcumin; NTG, nitroglycerin; QI, 25th percentile; Q3, 75th percentile; ST, sumatriptan.

sensitization process. ${ }^{34}$ Oxidative stress is also involved in central sensitization. ${ }^{35}$ It has been shown that the administration of glutamate induces an increase in intracellular reactive oxygen species in cultured neurons. ${ }^{36}$ The sensitization process refers to increased responsiveness to thermal, mechanical, or chemical stimuli, which may be translated to corresponding hyperalgesia. Activation or excitation of nociceptive nerve endings or fibers by these stimuli involves

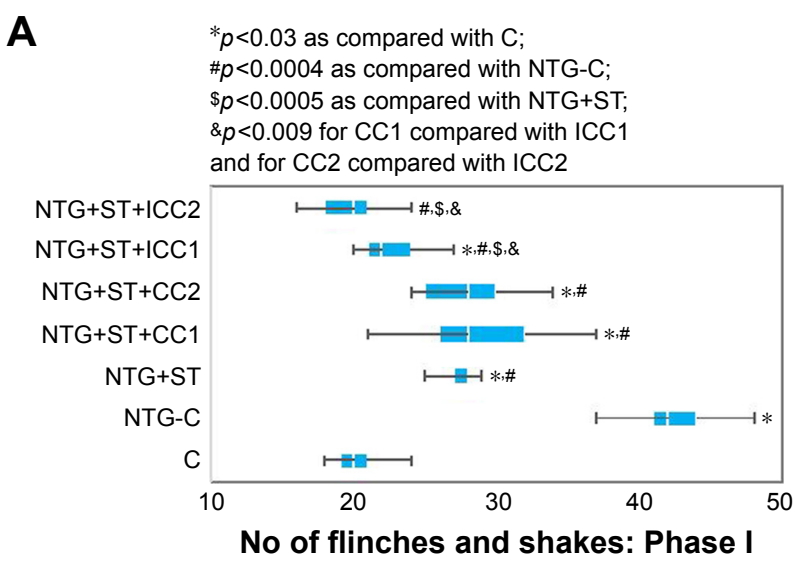

the generation of action potentials, which then travel to the central nervous system and may induce pain sensation. ${ }^{37}$ The formalin test, which implies injection of a formalin solution in the rat paw, indicates the excitation of nociceptors in previously sensitized animals by NTG administration. We assessed in our study both the first phase (the nociception phase) which consisted of direct action of a noxious stimulus modulated by a gate control mechanism and the second phase dominated by inflammation mechanisms. ${ }^{27}$ On the other hand, experimental studies showed that activation of the spinal 5-HT1A receptor by its selective agonists induced an antinociceptive effect in the increasing temperature hotplate test in rats and produced a dose-dependent decrease in N-methyl-D-aspartate receptor (glutamate specific receptors)mediated behavior of rats. ${ }^{38}$

\section{The effect of ST}

Because one of the most important mechanisms of migraine attack is a sudden decrease in 5-HT level, we tried to observe if there is a connection between the ST administration and the oxidative stress amplitude in an experimental migraine model. Our results showed that the ST administration significantly improved the oxidative stress parameters (see Tables 2 and 3). It was previously demonstrated that ST could repress the nociceptive pain by decreasing the activity of calcitonin gene-related protein via reducing NO formation. ${ }^{39}$ The 5-HT1B/1D agonist, ST (0.1, 1.0 and $10 \mathrm{nmol})$, also inhibited paw edema induced by experimental inflammation in rats, proving its anti-inflammatory properties. ${ }^{40}$ In our experimental study, ST was able to reduce the nociception

B

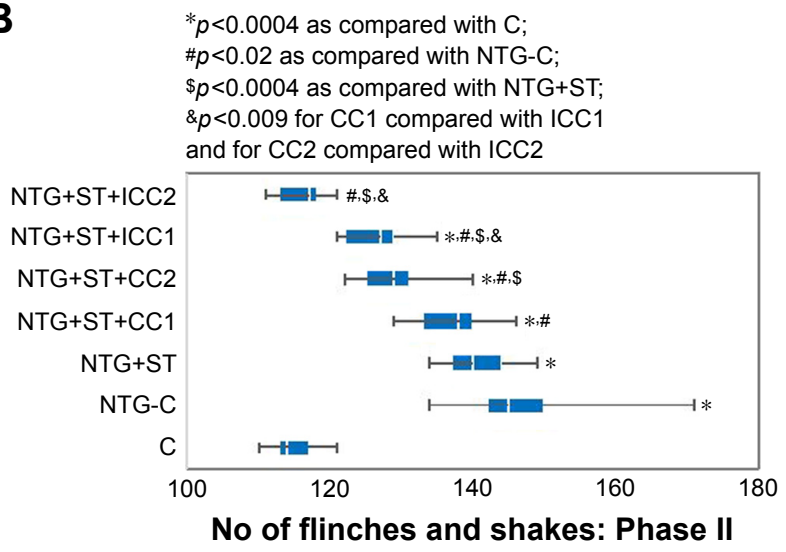

Figure 3 Number of flinches and shakes by groups: (A) Phase I, (B) Phase II. The box is given by the values of the first and third quartiles, the mid-line is given by the value of the median, and the whiskers are the minimum and maximum values. C is the control group (no medication), NTG-C is the group treated with nitroglycerin (NTG), NTG+ST is the group treated with NTG and sumatriptan (ST), NTG+ST+CCl is the group treated with NTG+ST and curcumin I mg/l00 g body weight (bw), NTG+ST+CC2 is the group treated with NTG+ST and curcumin $2 \mathrm{mg} / \mathrm{l} 00 \mathrm{~g}$ bw, NTG+ST+ICCl is the group treated with NTG+ST and liposomal curcumin I mg/I00 g bw, ad NTG+ST+ICC2 is the group treated with NTG+ST and liposomal curcumin $2 \mathrm{mg} / \mathrm{l} 00 \mathrm{~g}$ bw.

Abbreviations: C, control; CC, curcumin; ICC, liposomal curcumin; NTG, nitroglycerin; QI, 25th percentile; Q3, 75th percentile; ST, sumatriptan. 
process in both nociceptive phases (even in the second one dominated by an inflammation mechanism), as shown, by significantly decreasing the number of flinches and shakes after the formalin test (see Table 4). Furthermore, the reduction in vasodilation associated with neurogenic inflammation can lead to reduction of the nociceptive process. ST mediates a vasopressor response in the systemic circulation through 5-HT1 receptors, 5 min after administration. ${ }^{21} \mathrm{ST}$ has vasoconstrictive properties, as well as effects on neurogenic inflammation by decreasing the release of important molecules involved in neurogenic inflammation (such as substance $\mathrm{P}$ and the calcitonin gene-related peptide). ${ }^{41}$ The rapid action of ST can be translated in a longer anti-nociceptive effect by combination with nonsteroidal anti-inflammatory drugs like naproxen due to a longer effect on the inflammatory process. ${ }^{42}$

\section{The effect of liposomal curcumin}

Due to curcumin's anti-inflammatory ${ }^{43}$ and antioxidative properties $^{7}$ as well as its lack of toxicity and neuroprotective effect, ${ }^{44}$ we investigated the combination of the rapid effect of ST on the nociception process with the effects of curcumin in parenteral administration.

Both pharmaceutical forms (solution and liposomal curcumin) were effective in treating experimental migraine and reduced the nociceptive process (as indicated by a significantly decreased number of flinches and shakes in the groups treated with $\mathrm{CC}$ solution [CC1 and $\mathrm{CC} 2]$ ). Furthermore, liposomal curcumin, at both concentrations, significantly reduced the nociceptive process compared to the control groups (C group, NTG-C group, and NTG+ST group), being more efficient than the $\mathrm{CC}$ solutions. In an experimental pain study, the simultaneous oral administration of curcumin with the intraperitoneal administration of tramadol significantly attenuated mechanical allodynia and thermal hyperalgesia. ${ }^{45}$ Curcumin's anti-nociceptive mechanism is not clear but has proved to be part of the mechanisms involved in CX3CR1 expression, Mu and Delta opioid receptors, 5-HT (1A) receptors, or TNF- $\alpha$ expression. ${ }^{46}$ Curcumin was also found to attenuate the capsaicin-induced transient receptor potential of vanilloid 1 in experimental pain hypersensitivity. ${ }^{47}$ The intraperitoneal administration of curcumin blocked capsaicin-induced thermal hyperalgesia in a dose-dependent manner in trigeminal ganglion neurons. ${ }^{47}$

Curcumin exhibits stronger analgesic effects when it is administered parenterally in a liposomal form. Several previous studies demonstrated that it is possible to enhance the biodistribution of curcumin by encapsulation in various nanocarriers. The antinociceptive effect of curcumin nanoparticles in the experimental migraine model could also result from its ability to reduce neurogenic inflammation. ${ }^{48-50}$ Curcumin nanoformulation successfully inhibited experimental inflammation in a rat model, but at the same time, the employed concentration did not cause adverse effects on the brain tissue, as indicated by the brain lactic acid concentrations and measured neuronal apoptosis. ${ }^{51}$

The antioxidant effect of curcumin in addition to ST treatment was observed for all investigated groups (see Tables 2 and 3). The liposomal curcumin exerted a significantly greater antioxidant activity than the curcumin solution (see Tables 2 and 3). Its antioxidant effect could be attributed to its ability to scavenge free radicals such as hydroxyl radicals and peroxyl radicals. ${ }^{52-54}$ Curcumin can also directly interact with the superoxide anion, as shown by electron paramagnetic resonance, and can inhibit the activity of nuclear factor-kappaB (NF-kappaB), which is involved in the transcription of proinflammatory mediators. ${ }^{55}$ According to our results, the antioxidant effect of liposomal curcumin was significantly higher than that of the curcumin solution, for all the tested parameters (Figure 1). Data indicated that the MDA production, which reflects the degree of tissue and cell damage caused by lipid peroxidation, was reduced after the administration of curcumin, especially in the groups that received the liposomal formulation (Figure 1A). The decrease in MDA values after the administration of liposomal curcumin was shown by other researchers in oxidative stress conditions induced by experimental renal ischemia. ${ }^{56}$ The ability to reduce the NO formation has also been demonstrated in previous studies. ${ }^{57,58}$ It has been shown that in brain tissue, the inhibition of inducible nitric oxide synthase can be closely correlated with increasing concentrations of the administered curcuminoids. ${ }^{59}$ Curcumin can also reduce the amount of nitrite formed by the reaction between oxygen and nitric oxide, ${ }^{60}$ which is an important mechanism of reducing oxidative stress. In addition, multifunctional nanocarriers seem to play a key role, considering that these pharmaceutical forms show enhanced characteristics such as biocompatibility and also have limited side effects. ${ }^{61}$ The administration of curcumin encapsulated in nanocarriers led to an elevated antioxidant effect compared to the free curcumin. ${ }^{62,63}$ The neuroprotective effect of curcumin nanoformulations after BBB disruption $^{64}$ can also be important since in migraine attacks there is an increased NO release associated with vasodilation ${ }^{65}$ that can lead to BBB hyperpermeability. ${ }^{66,67}$ The neuroprotective effect of nanocurcumin combined with omega-3 fatty 
acids, in an experimental migraine model, has also been reported by Abdolahi et al, and has been attributed to its anti-inflammatory properties that occur as a result of TNF- $\alpha$ serum level reduction. ${ }^{68}$ The effect on NOx production was also more important for the liposomal curcumin group in our study (Figure 1B). The improvement of TOS (Figure 1C) and TAC (Figure 2B) parameters when curcumin was in addition to ST treatment had been demonstrated for all our study groups, with more significant results obtained for liposomal curcumin (1CC groups). The reduction of TOS and improvement of TAC in the curcumin-treated groups was also demonstrated in an experimental ovarian ischemiareperfusion model in rats. ${ }^{69}$ The effect of nanocurcumin on TOS and TAC parameters have not been reported in previous studies. Thiols that are able to mediate redox signaling processes as response to oxidative stress were significantly increased in our study groups, especially for the groups that received liposomal curcumin (Figure 2A). The underlying mechanism for the increase in the thiol level after curcumin administration could be the induction of glutathione biosynthesis and inhibition of the NF-kappaB activation. ${ }^{70,71}$ Multifunctional glutathione, particularly in reduced form (GSH), is an intracellular thiol found in all tissues with an important role in protecting against oxidative stress. ${ }^{72}$ Our study demonstrated that the administration of liposomal curcumin (at both concentrations) was able to significantly enhance the thiol level compared to the control groups, while ST alone or ST associated with the curcumin solution did not significantly improve the thiol level. This phenomenon can be explained by an increased metabolic stability of liposomal curcumin and a better tissue distribution, which is associated with a lower rate of metabolization to tetrahydrocurcumin and enhanced antioxidative properties. ${ }^{73}$

\section{Study limitations}

A rigorous experimental design was applied to assess the effect of the intravenous administration of curcumin-loaded liposomes when in addition to ST treatment in an experimental animal migraine model. Despite the rigor of the applied experimental design, several limitations can be listed. First, the formalin test for nociception may not be the ideal test since the results could be affected by peripheral tissue temperature or other factors influencing the peripheral inflammation. ${ }^{27}$ A computational model developed by Fischer et $\mathrm{al}^{74}$ supports the biphasic response, the interphase being the result of hyperpolarization and transient inactivation, followed by recovery prior to decrease in formalin concentration below threshold. However, the $1 \%$ formalin injection used in our design assured the absence of long-lasting hypersensitivity and peripheral inflammation (reported for $2 \%$ and $5 \%$ in a spinal nerve injury model $)^{75}$ and thus the comfort of animals. Despite its limitations, the formalin test is still currently used in the evaluation of both pain and inflammation in animal models. ${ }^{76,77}$ Second, the concentration of curcumin and/or ST in the blood, as well as in the brain tissue, was not quantified. This kind of measurements could bring useful information, but a separate design using different forms of curcumin must be tested. Our research group, therefore, sets to pursue this goal in further studies.

\section{Conclusion}

The liposomal curcumin at a dose of $2 \mathrm{mg} / 100 \mathrm{~g}$ bw seems to enhance the antioxidative effect of ST. However, further studies, including on liposomal curcumin alone, are needed to confirm our findings. The use of nanotechnology in medicine could be an appropriate means to enhance the efficiency of different treatments. The difference between ST in single administration and in combination with conventional curcumin is marginal, but the association with liposomal curcumin proved to be efficient in our experimental migraine model. The efficiency of liposomal curcumin has to be tested in clinical conditions and could represent an improved therapeutic modality for migraine attacks. Therefore, liposomal curcumin could be useful for improving the bioavailability and efficacy of this compound.

\section{Disclosure}

The authors report no conflicts of interest in this work.

\section{References}

1. Vos T, Flaxman AD, Naghavi M, et al. Years lived with disability (YLDs) for 1160 sequelae of 289 diseases and injuries 1990-2010: a systematic analysis for the Global Burden of Disease Study 2010. Lancet. 2012;380(9859):2163-2196.

2. Tassorelli C, Greco R, Wang D, Sandrini G, Nappi G. Prostaglandins, glutamate and nitric oxide synthase mediate nitroglycerin-induced hyperalgesia in the formalin test. Eur J Pharmacol. 2006;534(1-3): 103-107.

3. Ferrari LF, Levine JD, Green PG. Mechanisms mediating nitroglycerininduced delayed-onset hyperalgesia in the rat. Neuroscience. 2016; 317:121-129.

4. Borkum JM. Migraine triggers and oxidative stress: a narrative review and synthesis. Headache. 2016;56(1):12-35.

5. Geyik S, Altunisık E, Neyal AM, Taysi S. Oxidative stress and DNA damage in patients with migraine. $J$ Headache Pain. 2016;17:10

6. Carrasco C, Naziroğlu M, Rodríguez AB, Pariente JA. Neuropathic pain: delving into the oxidative origin and the possible implication of transient receptor potential channels. Front Physiol. 2018;9:95.

7. Bulboacă A, Bolboacă S, Suci S. Protective effect of curcumin in fructose-induced metabolic syndrome and in streptozotocin-induced diabetes in rats. Iran J Basic Med Sci. 2016;19(6):585-593. 
8. Bulboacă AE, Bolboacă SD, Stănescu IC, Sfrângeu CA, Bulboacă AC. Preemptive analgesic and antioxidant effect of curcumin for experimental migraine. Biomed Res Int. 2017;2017:4754701.

9. Hewlings SJ, Kalman DS. Curcumin: a review of its' effects on human health. Foods. 2017;6(10). pii: E92.

10. Chiu SS, Lui E, Majeed M, et al. Differential distribution of intravenous curcumin formulations in the rat brain. Anticancer Res. 2011;31(3):907-911.

11. Zheng Z, Sun Y, Liu Z, Zhang M, Li C, Cai H. The effect of curcumin and its nanoformulation on adjuvant-induced arthritis in rats. Drug Des Devel Ther. 2015;9:4931-4942.

12. Soveyd N, Abdolahi M, Djalali M, et al. The combined effects of $\omega-3$ fatty acids and nano-curcumin supplementation on intercellular adhesion molecule-1 (ICAM-1) gene expression and serum levels in migraine patients. CNS Neurol Disord Drug Targets. 2018;16(10): $1120-1126$.

13. Gera M, Sharma N, Ghosh M, et al. Nanoformulations of curcumin: an emerging paradigm for improved remedial application. Oncotarget. 2017;8(39):66680-66698

14. Ganesan P, Ko HM, Kim IS, Choi DK. Recent trends in the development of nanophytobioactive compounds and delivery systems for their possible role in reducing oxidative stress in Parkinson's disease models. Int J Nanomedicine. 2015;10:6757-6772.

15. Kowalska M, Prendecki M, Kozubski W, Lianeri M, Dorszewska J. Molecular factors in migraine. Oncotarget. 2016;7(31):50708-50718.

16. Tokuoka K, Takayanagi R, Toyabe M, Watanabe M, Kitagawa Y, Yamada Y. Theoretical analysis of headache recurrence in patients administered triptans for migraine based on receptor occupancy. J Headache Pain. 2015;16:71.

17. Aggarwal M, Puri V, Puri S. Serotonin and CGRP in migraine. Ann Neurosci. 2012;19(2):88-94.

18. Becerra L, Bishop J, Barmettler G, et al. Triptans disrupt brain networks and promote stress-induced CSD-like responses in cortical and subcortical areas. J Neurophysiol. 2016;115(1):208-217.

19. Stoyanova II, Lazarov NE. Localization of nitric oxide synthase in rat trigeminal primary afferent neurons using NADPH-diaphorase histochemistry. J Mol Histol. 2005;36(3):187-193.

20. Berman NE, Puri V, Chandrala S, et al. Serotonin in trigeminal ganglia of female rodents: relevance to menstrual migraine. Headache. 2006;46(8):1230-1245.

21. Macintyre PD, Bhargava B, Hogg KJ, Gemmill JD, Hillis WS. The effect of i.v. sumatriptan, a selective 5-HT1-receptor agonist on central haemodynamics and the coronary circulation. Br J Clin Pharmacol. 1992;34(6):541-546.

22. Evans RW, Tepper SJ, Shapiro RE, Sun-Edelstein C, Tietjen GE. The FDA alert on serotonin syndrome with use of triptans combined with selective serotonin reuptake inhibitors or selective serotonin-norepinephrine reuptake inhibitors: American Headache Society position paper. Headache. 2010;50(6):1089-1099.

23. Sesarman A, Tefas L, Sylvester B, et al. Anti-angiogenic and antiinflammatory effects of long-circulating liposomes co-encapsulating curcumin and doxorubicin, on C26 murine colon cancer cells. Pharmacol Rep. 2018;70(2):331-339.

24. Tefas LR, Sylvester B, Tomuta I, et al. Development of antiproliferative long-circulating liposomes co-encapsulating doxorubicin and curcumin, through the use of a quality-by-design approach. Drug Des Devel Ther. 2017;11:1605-1621.

25. Sufka KJ, Staszko SM, Johnson AP, Davis ME, Davis RE, Smitherman TA. Clinically relevant behavioral endpoints in a recurrent nitroglycerin migraine model in rats. J Headache Pain. 2016;17:40.

26. Bates EA, Nikai T, Brennan KC, etal. Sumatriptan alleviates nitroglycerininduced mechanical and thermal allodynia in mice. Cephalalgia. 2010; 30(2):170-178.

27. Tjølsen A, Berge OG, Hunskaar S, Rosland JH, Hole K. The formalin test: an evaluation of the method. Pain. 1992;51(1):5-17.

28. Hunskaar S, Hole K. The formalin test in mice: dissociation between inflammatory and non-inflammatory pain. Pain. 1987;30(1): 103-114.
29. Mohammad A, Ali N, Reza B, Ali K. Effect of ascorbic acid supplementation on nitric oxide metabolites and systolic blood pressure in rats exposed to lead. Indian J Pharmacol. 2010;42(2):78-81.

30. Yagl K. Assay for blood plasma and serum peroxides. Methods Enzymol. 1984;105:28-31.

31. Parvu AE, Parvu M, Vlase L, Miclea P, Mot AC, Silaghi-Dumitrescu R. Anti-inflammatory effects of Allium schoenoprasum L. leaves. J Physiol Pharmacol. 2014;65(2):309-315.

32. Ellman GL. A colorimetric method for determining low concentrations of mercaptans. Arch Biochem Biophys. 1958;74(2):443-450.

33. Merino JJ, Arce C, Naddaf A, Bellver-Landete V, Oset-Gasque MJ, González MP. The nitric oxide donor SNAP-induced amino acid neurotransmitter release in cortical neurons. Effects of blockers of voltage-dependent sodium and calcium channels. PLoS One. 2014; 9(3):e90703.

34. Nagy-Grócz G, Tar L, Bohár Z, et al. The modulatory effect of anandamide on nitroglycerin-induced sensitization in the trigeminal system of the rat. Cephalalgia. 2016;36(9):849-861.

35. Schwartz ES, Lee I, Chung K, Chung JM. Oxidative stress in the spinal cord is an important contributor in capsaicin-induced mechanical secondary hyperalgesia in mice. Pain. 2008;138(3):514-524.

36. Bindokas VP, Jordán J, Lee CC, Miller RJ. Superoxide production in rat hippocampal neurons: selective imaging with hydroethidine. J Neurosci. 1996;16(4):1324-1336.

37. Petho G, Reeh PW. Sensory and signaling mechanisms of bradykinin, eicosanoids, platelet-activating factor, and nitric oxide in peripheral nociceptors. Physiol Rev. 2012;92(4):1699-1775.

38. Mjellem N, Lund A, Eide PK, Størkson R, Tjølsen A. The role of 5-HT1A and 5-HT1B receptors in spinal nociceptive transmission and in the modulation of NMDA induced behaviour. Neuroreport. 1992;3(12): 1061-1064.

39. Bellamy J, Bowen EJ, Russo AF, Durham PL. Nitric oxide regulation of calcitonin gene-related peptide gene expression in rat trigeminal ganglia neurons. Eur J Neurosci. 2006;23(8):2057-2066.

40. Daher JB, de Melo MD, Tonussi CR. Evidence for a spinal serotonergic control of the peripheral inflammation in the rat. Life Sci. 2005;76(20): 2349-2359.

41. Blumenfeld A, Gennings C, Cady R. Pharmacological synergy: the next frontier on therapeutic advancement for migraine. Headache. 2012;52(4):636-647.

42. Smith TR, Sunshine A, Stark SR, Littlefield DE, Spruill SE, Alexander WJ. Sumatriptan and naproxen sodium for the acute treatment of migraine. Headache. 2005;45(8):983-991.

43. Zhao S, Ma L, Cao C, Yu Q, Chen L, Liu J. Curcumin-loaded redox response of self-assembled micelles for enhanced antitumor and antiinflammation efficacy. Int J Nanomedicine. 2017;12:2489-2504.

44. Monroy A, Lithgow GJ, Alavez S. Curcumin and neurodegenerative diseases. Biofactors. 2013;39(1):122-132.

45. Ceyhan D, Kocman AE, Yildirim E, Ozatik O, Aydin S, Kose A. Comparison of the effects of curcumin, tramadol and surgical treatments on neuropathic pain induced by chronic constriction injury in rat. Turk Neurosurg. 2018;28(2):288-295.

46. Kapoor S. Curcumin and its emerging role in pain modulation and pain management. Korean J Pain. 2012;25(3):202-203.

47. Yeon KY, Kim SA, Kim YH, et al. Curcumin produces an antihyperalgesic effect via antagonism of TRPV1. J Dent Res. 2010;89(2):170-174.

48. Sun D, Zhuang X, Xiang X, et al. A novel nanoparticle drug delivery system: the anti-inflammatory activity of curcumin is enhanced when encapsulated in exosomes. Mol Ther. 2010;18(9):1606-1614.

49. Yallapu MM, Nagesh PK, Jaggi M, Chauhan SC. Therapeutic applications of curcumin nanoformulations. AAPS J. 2015;17(6):1341-1356.

50. Di Martino P, Censi R, Gigliobianco MR, et al. Nano-medicine improving the bioavailability of small molecules for the prevention of neurodegenerative diseases. Curr Pharm Des. 2017;23(13):1897-1908.

51. Singh AK, Jiang Y, Gupta S, Younus M, Ramzan M. Anti-inflammatory potency of nano-formulated puerarin and curcumin in rats subjected to the lipopolysaccharide-induced inflammation. J Med Food. 2013; 16(10):899-911. 
52. Agnihotri N, Mishra PC. Scavenging mechanism of curcumin toward the hydroxyl radical: a theoretical study of reactions producing ferulic acid and vanillin. J Phys Chem A. 2011;115(49):14221-14232.

53. Tharakan B, Hunter FA, Smythe WR, Childs EW. Curcumin inhibits reactive oxygen species formation and vascular hyperpermeability following haemorrhagic shock. Clin Exp Pharmacol Physiol. 2010; 37(9):939-944.

54. Fujisawa S, Atsumi T, Ishihara M, Kadoma Y. Cytotoxicity, ROSgeneration activity and radical-scavenging activity of curcumin and related compounds. Anticancer Res. 2004;24(2B):563-569.

55. Biswas SK, McClure D, Jimenez LA, Megson IL, Rahman I. Curcumin induces glutathione biosynthesis and inhibits NF-kappaB activation and interleukin-8 release in alveolar epithelial cells: mechanism of free radical scavenging activity. Antioxid Redox Signal. 2005;7(1-2):32-41.

56. Xu Y, Hu N, Jiang W, Yuan HF, Zheng DH. Curcumin-carrying nanoparticles prevent ischemia-reperfusion injury in human renal cells. Oncotarget. 2016;7(52):87390-87401.

57. Chan MM, Adapala NS, Fong D. Curcumin overcomes the inhibitory effect of nitric oxide on Leishmania. Parasitol Res. 2005; 96(1):49-56.

58. Yu L, Yi J, Ye G, et al. Effects of curcumin on levels of nitric oxide synthase and AQP-4 in a rat model of hypoxia-ischemic brain damage. Brain Res. 2012;1475:88-95.

59. Begum AN, Jones MR, Lim GP, et al. Curcumin structure-function, bioavailability, and efficacy in models of neuroinflammation and Alzheimer's disease. J Pharmacol Exp Ther. 2008;326(1):196-208.

60. Sreejayan, Rao MN. Nitric oxide scavenging by curcuminoids. JPharm Pharmacol. 1997;49(1):105-107.

61. Siafaka PI, Üstündağ Okur N, Karavas E, Bikiaris DN. Surface modified multifunctional and stimuli responsive nanoparticles for drug targeting: current status and uses. Int J Mol Sci. 2016;17(9). pii: E1440.

62. Yu H, Li J, Shi K, Huang Q. Structure of modified $\varepsilon$-polylysine micelles and their application in improving cellular antioxidant activity of curcuminoids. Food Funct. 2011;2(7):373-380.

63. Mohajeri M, Sadeghizadeh M, Najafi F, Javan M. Polymerized nanocurcumin attenuates neurological symptoms in EAE model of multiple sclerosis through down-regulation of inflammatory and oxidative processes and enhancing neuroprotection and myelin repair. Neuropharmacology. 2015;99:156-167.

64. Zhang ZY, Jiang M, Fang J, et al. Enhanced therapeutic potential of nano-curcumin against subarachnoid hemorrhage-induced blood-brain barrier disruption through inhibition of inflammatory response and oxidative stress. Mol Neurobiol. 2017;54(1):1-14.
65. Greco R, Ferrigno A, Demartini C, et al. Evaluation of ADMADDAH-NOS axis in specific brain areas following nitroglycerin administration: study in an animal model of migraine. $J$ Headache Pain. 2015;16:560.

66. Song TT, Bi YH, Gao YQ, et al. Systemic pro-inflammatory response facilitates the development of cerebral edema during short hypoxia. J Neuroinflammation. 2016;13(1):63.

67. DosSantos MF, Holanda-Afonso RC, Lima RL, DaSilva AF, MouraNeto $\mathrm{V}$. The role of the blood-brain barrier in the development and treatment of migraine and other pain disorders. Front Cell Neurosci. 2014;8:302.

68. Abdolahi M, Tafakhori A, Togha M, et al. The synergistic effects of $\omega-3$ fatty acids and nano-curcumin supplementation on tumor necrosis factor (TNF)- $\alpha$ gene expression and serum level in migraine patients. Immunogenetics. 2017;69(6):371-378.

69. Eser A, Hizli D, Haltas H, et al. Effects of curcumin on ovarian ischemiareperfusion injury in a rat model. Biomed Rep. 2015;3(6):807-813.

70. Edwards RL, Luis PB, Varuzza PV, et al. The anti-inflammatory activity of curcumin is mediated by its oxidative metabolites. J Biol Chem. 2017;292:21243-21252.

71. Sandur SK, Ichikawa H, Pandey MK, et al. Role of pro-oxidants and antioxidants in the anti-inflammatory and apoptotic effects of curcumin (diferuloylmethane). Free Radic Biol Med. 2007;43(4):568-580.

72. Fra A, Yoboue ED, Sitia R. Cysteines as redox molecular switches and targets of disease. Front Mol Neurosci. 2017;10:167.

73. Matabudul D, Pucaj K, Bolger G, Vcelar B, Majeed M, Helson L. Tissue distribution of (Lipocurc ${ }^{\mathrm{TM}}$ ) liposomal curcumin and tetrahydrocurcumin following two- and eight-hour infusions in Beagle dogs. Anticancer Res. 2012;32(10):4359-4364.

74. Fischer M, Carli G, Raboisson P, Reeh P. The interphase of the formalin test. Pain. 2014;155(3):511-521.

75. Salinas-Abarca AB, Avila-Rojas SH, Barragán-Iglesias P, PinedaFarias JB, Granados-Soto V. Formalin injection produces longlasting hypersensitivity with characteristics of neuropathic pain. Eur $J$ Pharmacol. 2017;797:83-93.

76. Pachenari N, Azizi H, Ghasemi E, Azadi M, Semnanian S. Exposure to opiates in male adolescent rats alters pain perception in the male offspring. Behav Pharmacol. 2018;29(2 and 3 - Special Issue):255-260.

77. Birmann PT, Sousa FSS, de Oliveira DH, et al. 3-(4-Chlorophenylselanyl)1-methyl-1H-indole, a new selenium compound elicits an antinociceptive and anti-inflammatory effect in mice. Eur J Pharmacol. 2018 827:71-79.
International Journal of Nanomedicine

\section{Publish your work in this journal}

The International Journal of Nanomedicine is an international, peerreviewed journal focusing on the application of nanotechnology in diagnostics, therapeutics, and drug delivery systems throughout the biomedical field. This journal is indexed on PubMed Central, MedLine, CAS, SciSearch $®$, Current Contents $\AA /$ Clinical Medicine,

\section{Dovepress}

Journal Citation Reports/Science Edition, EMBase, Scopus and the Elsevier Bibliographic databases. The manuscript management system is completely online and includes a very quick and fair peer-review system, which is all easy to use. Visit http://www.dovepress.com/ testimonials.php to read real quotes from published authors. 